\title{
Thermophysics of thallium alkanoates
} IV. Heat capacity and thermodynamic
functions of thallium(I) n-dodecanoate
from 7 to $470 \mathrm{~K}^{a}$

\author{
F. L. LÓPEZ DE LA FUENTE. ${ }^{b}$ E. F. WESTRUM, JR..
}

Department of Chemistry, University of Michigan. Ann Arbor, MI 48109, U.S.A.

J. A. R. CHEDA, and

Departamento de Quimica Fisica, Facultad de Ciencias Quimicas, Universidad Complutense, 28040 Madrid. Spain

F. FERNÁNDEZ-MARTÍN

Instituto del Frio, C.S.I.C., 28040 Madrid, Spain

(Received 6 April 1987)

\begin{abstract}
The thermal behavior of thallium(I) $n$-dodecanoate was studied by adiabatic calorimetry from 6 to $350 \mathrm{~K}$ and by d.s.c. from 230 through $470 \mathrm{~K}$. The agreement between the results (temperature and thermal functions of transitions and heat capacity) from both methods was within the experimental error over the common temperature range. Several phases were observed in the sample. Four of the five solid-to-solid transitions appeared in the common temperature range of both techniques. The two lowest-temperature transitions appear as a bifurcated pair (at 282.65 and $284.8 \mathrm{~K}$ ) with $\left(C_{p, \mathrm{~m}} / R\right) \approx 250$ and 450 , respectively. The third and fourth occur at 293.1 and $312.1 \mathrm{~K}$ with $\left(C_{p, \mathrm{~m}} / R\right) \approx 250$ and 14000 . Above $350 \mathrm{~K}$ three more transitions were measured by d.s.c.: solid-to-solid, solid-to-mesophase, and mesophaseto-isotropic-liquid transformations at $356.6,400.1$, and $471.5 \mathrm{~K}$. The corresponding values of $\Delta_{\mathrm{rrs}} S_{\mathrm{m}}^{\prime \prime} / K$ for the seven transitions were $0.91_{0}, 1.11_{1}, 0.71_{0}, 2.07_{5}, 0.6_{9}, 1.6_{4}$, and 0.50 . Smoothed thermodynamic values are tabulated at selected temperatures through the "clearing" point.
\end{abstract}

\section{Introduction}

The previous papers in this series ${ }^{(1-3)}$ describe the thermophysical properties of thallium(I) $n$-hexanoate, $n$-heptanoate, and $n$-tetradecanoate. For each, several solid-to-solid phase transitions were observed and their temperatures, enthalpies, and entropies were measured. The complete morphology of the heat-capacity curve from $5 \mathrm{~K}$ to about $450 \mathrm{~K}$ for the three substances was obtained as well.

\footnotetext{
${ }^{a}$ The previous papers in this series are references 1,2 , and 3 .

${ }^{b}$ Present address: Departamento de Quimica Física, Facultad de Ciencias Químicas, Universidad Complutense, 28040 Madrid, Spain.
} 
This paper concerns another long-chain member of the series: thallium(I) $n$-dodecanoate. Previous studies ${ }^{(4-7)}$ identify mainly transition temperatures and. seldom, enthalpies and entropies of transitions occurring above $300 \mathrm{~K}$, by using microscopic observations, d.s.c., d.t.a., and hot-stage polarizing microscopy. We have measured the heat capacity of the sample combining sub-ambient adiabatic equilibrium calorimetry from 6 to $350 \mathrm{~K}$ with d.s.c. above $230 \mathrm{~K}$.

Five solid-to-solid transitions were found in addition to fusion (solid to mesomorphic phase) and to "clearing" (mesomorphic phase to isotropic liquid). In summary:

$$
\begin{aligned}
& \text { Crystal VI } \stackrel{282.6, \mathrm{~K}}{\longrightarrow} \text { Crystal V } \stackrel{284.8 \mathrm{~K}}{\longrightarrow} \text { Crystal IV } \stackrel{293.1 \mathrm{~K}}{\longrightarrow} \text { Crystal III } \stackrel{312, \mathrm{~K}}{\longrightarrow} \text { Crystal II } \\
& \stackrel{156.6 \mathrm{~K}}{\longrightarrow} \text { Crystal I } \stackrel{400.1 \mathrm{~K}}{\longrightarrow} \text { Mesomorphic liquid } \stackrel{471.5 \mathrm{~K}}{\longrightarrow} \text { Isotropic liquid. }
\end{aligned}
$$

\section{Experimental}

Thallium(I) $n$-dodecanoate was prepared by reacting Fluka puriss ( $>99.5$ moles per cent pure by g.c. at the origin) $n$-dodecanoic acid dissolved in anhydrous methanol with a slight excess $(\approx 5$ per cent $)$ of Fluka puriss $\mathrm{Tl}_{2} \mathrm{CO}_{3}(>99$ moles per cent pure) suspended in the same solvent. After refluxing under stirring (for about $3 \mathrm{~h}$ ) and separating some unreacted carbonate by filtration, the solution was concentrated until incipient crystallization, which was completed by precipitation with dry diethyl ether. The recovered solid salt was further purified by repeated recrystallization with absolute ethanol and finally dried to constant mass at about $300 \mathrm{~K}$ under vacuum. Infrared spectroscopic determinations showed no traces of water or free acid. Moreover, several d.s.c. purity determinations by fractionalfusion techniques indicated a mean value of $(99.83 \pm 0.05)$ moles per cent of liquidsoluble solid-insoluble purity.

The calorimetric measurements at Ann Arbor between 6 and $350 \mathrm{~K}$ were made in the Mark X cryostat described previously. ${ }^{(8)}$ The intermittent-heating adiabatic equilibrium method was utilized. The programming, data logging, and calorimetry were done by automated computerization as described elsewhere. ${ }^{(9)}$

The sample loaded into a gold-plated copper calorimeter (designation W-62) had a mass of $40.200 \mathrm{~g}$ corresponding to an amount of substance of $0.099579 \mathrm{~mol}$ with a molar mass $403.70 \mathrm{~g} \cdot \mathrm{mol}^{-1}$ (on the basis of the 1978 IUPAC relative atomic masses). The buoyancy corrections were calculated assuming a density of $2.4 \mathrm{~g} \cdot \mathrm{cm}^{-3}$. (No crystallographic information on density is available for thallium(I) $n$-dodecanoate or adjacent members of the homologous series. Thallium acetate has a density of $3.6 \mathrm{~g} \cdot \mathrm{cm}^{-3}$ ). Following evacuation, $3.47 \mathrm{kPa}$ of purified helium was added to the calorimeter to promote thermal equilibration. The calorimeter was then sealed within a chamber with a small pressure of purified helium gas by a remotely turned wrench operating a hexagonal cap which pressed a gold gasket against the circular knife edge of the vessel.

The thermal history outlined below shows the detail of the thermal cycles to which the sample was subjected; the solid arrows show cooling periods while dashed arrows show data-acquisition intervals: 
$300 \mathrm{~K} \stackrel{2 \mathrm{~h}}{\longrightarrow} 249 \mathrm{~K} \underset{\text { Series }}{\stackrel{8 \mathrm{~h}}{\longrightarrow}} 332 \mathrm{~K} \stackrel{11.5 \mathrm{~h}}{\longrightarrow} 191 \mathrm{~K} \stackrel{7 \mathrm{~h}}{\longrightarrow} 300 \mathrm{~K}(3 \mathrm{~d}) \stackrel{2 \mathrm{~h}}{\longrightarrow}$

$$
\begin{aligned}
& 248 \mathrm{~K} \underset{\text { Series } 1 \mathrm{II}}{\stackrel{4 \mathrm{~h}}{\longrightarrow}} 343 \mathrm{~K} \stackrel{13.5 \mathrm{~h}}{\longrightarrow} 212 \mathrm{~K} \underset{\text { Series III }}{\stackrel{6.8 \mathrm{~h}}{\longrightarrow}} 342 \mathrm{~K} \stackrel{16 \mathrm{~h}}{\longrightarrow} 249 \mathrm{~K} \underset{\text { Serie } \rightarrow \mathrm{V}}{\stackrel{5.3 \mathrm{~h}}{\longrightarrow}} \\
& 348 \mathrm{~K} \underset{\text { Series } \mathrm{V}}{\stackrel{14.5 \mathrm{~h}}{\longrightarrow}} 92 \mathrm{~K} \stackrel{8 \mathrm{~h}}{\longrightarrow} 91 \mathrm{~K} \underset{\text { Series VI }}{\stackrel{13.8 \mathrm{~h}}{\longrightarrow}} 282 \mathrm{~K} \underset{\text { Series Vll }}{\stackrel{10.8 \mathrm{~h}}{\rightarrow}} 314 \mathrm{~K} \stackrel{13 . \mathrm{h}}{\longrightarrow} 253 \mathrm{~K} \stackrel{1 \mathrm{~h}}{\longrightarrow}
\end{aligned}
$$

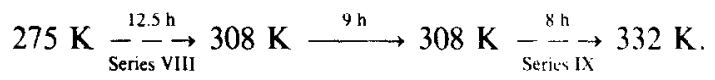

A Perkin-Elmer DSC-2C at Madrid provided with the Intracooler-2 unit for sub-ambient temperatures was used between 230 and $480 \mathrm{~K}$. Its temperature scale for the region of interest was calibrated by the melting temperatures of the usual high-purity standards: $n$-undecane, $n$-tridecane, $n$-pentadecane, gallium, indium, tin, stearic (octadecanoic) acid, and benzoic acid. The enthalpies of transitions were determined on several samples (about $15 \mathrm{mg}$ ) using high-purity indium (>99.999 moles per cent) as standard material for the calibration of power. For the heatcapacity determinations, synthetic sapphire disks of different masses were used as external standards. ${ }^{(10)}$ The samples were weighed with a precision of $\pm 2 \mathrm{mg}$. Special care was exercised to place the radiation lids over the panholders in a reproducible orientation so as to reduce as far as possible the changes in the heat-loss patterns in different scans. The results obtained by d.s.c. were the mean values from at least four different samples, ranging between 10 and $20 \mathrm{mg}$.

\section{Results and discussion}

Approximately 190 heat-capacity determinations were made in 9 series of measurements by adiabatic calorimetry. The experimental results at the mean temperature of each measurement are listed in table 1 in chronological sequence by series, so that the temperature increment of a determination may be inferred from the mean temperatures of adjacent determinations. The standard deviations of the heat capacities by adiabatic calorimetry are 3 per cent at $6 \mathrm{~K}, 0.4$ per cent at $20 \mathrm{~K}$. and $<0.1$ per cent above $50 \mathrm{~K}$.

The heat capacity of the sample represented about 90 per cent of the total (sample + helium + calorimeter) at $10 \mathrm{~K}$ and was always higher than 60 per cent of the total (the minimum value being reached at about $200 \mathrm{~K}$ ).

The d.s.c. results are listed in table 2 . No d.s.c. measurements of the heat capacity were made at temperatures above $470 \mathrm{~K}$ because decomposition of the sample starts within about $10 \mathrm{~K}$ of this limit.

Heat-capacity results from both adiabatic and d.s.c. measurements are shown in figure 1. Good agreement between both sets was obtained over the common temperature range. The standard deviations in the d.s.c. measurements are generally about 1 to 2 per cent. Figure 2 presents an expanded plot of the region between 250 and $340 \mathrm{~K}$ the better to reveal the features of the transitions.

Between the solid III-to-II and solid II-to-I transitions, a broad and diffused hump with a maximum at about $345 \mathrm{~K}$ is observed in the $C_{p, \mathrm{~m}} / R$ against $T$ curve. A similar behavior has been described already for the equivalent phase (the penultimate solid phase before the mesophase in thallium(I) $n$-tetradeconoate $)^{(3)}$ 
TABLE 1. Experimental molar heat capacities of thallium(I) $n$-dodecanoate; $R=8.3144 \mathrm{~J} \cdot \mathrm{K}^{-1} \cdot \mathrm{mol}^{-1}$

\begin{tabular}{|c|c|c|c|c|c|c|c|c|c|c|c|}
\hline$T / \mathbf{K}$ & $C_{p, \mathrm{~m}} / R$ & $T / \mathrm{K}$ & $C_{p, \mathrm{~m}} / R$ & $T / \mathbf{K}$ & $C_{p, \mathrm{~m}} / R$ & $T / \mathrm{K}$ & $C_{p, \mathrm{~m}} / R$ & $T / \mathrm{K}$ & $C_{p . \mathrm{m}} / R$ & $T / \mathrm{K}$ & $C_{p, \mathrm{~m}} / R$ \\
\hline \multicolumn{2}{|c|}{ Series I } & 281.01 & 69.35 & 20.11 & 3.315 & 118.32 & 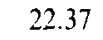 & 2.08 & 62.67 & 62 & 73 \\
\hline 253.53 & 38.01 & 300.06 & & 21.24 & & 123.39 & & 293.06 & & & \\
\hline 260.5 & 39 . & & 85.96 & 22.50 & 3.9 & 128.46 & & 293.49 & 149.5 & & \\
\hline & 40.6 & 334.48 & 73.36 & 23.91 & 4.3 & 133.54 & 2. & & & & \\
\hline 272 & 42.4 & 1.18 & 76.51 & 5.32 & 4.7 & 138.64 & 2 & & & & 87.17 \\
\hline & 49.0 & \multirow{2}{*}{\multicolumn{2}{|c|}{ Series IV }} & 26.73 & 5.1 & 143.74 & & & & 292.92 & 120.4 \\
\hline 282.40 & 123.80 & & & 28.15 & 5.555 & 149.34 & & & & & 8 \\
\hline 285.07 & 151.39 & 56.98 & & 29.81 & 6.020 & 155.45 & 26.21 & 30 & 59 & 29 & 172.3 \\
\hline 290.15 & 85 & & & & & & & & & & 69 \\
\hline & & 9 & 71.51 & 88 & 7.0 & 16 & 2 & 15 & 66 & 29. & 55.42 \\
\hline 301.96 & 58.11 & & & & & & & & 107. & 40 & 58. \\
\hline 307.87 & 63.47 & 300.57 & 57.3 & 38.16 & 8.3 & 179.96 & 28.64 & 312.08 & 1452 & \multirow{2}{*}{\multicolumn{2}{|c|}{ Series IX }} \\
\hline 314.75 & 141.74 & 312.53 & & & & .09 & & & & & \\
\hline 325.50 & 70.82 & 326.33 & 70.54 & 42.92 & 9.576 & 192.23 & 29.88 & 312.15 & 2298 & 308.45 & 63.10 \\
\hline \multirow{2}{*}{\multicolumn{2}{|c|}{ Series II }} & & 72 & 45.21 & 10.1 & 198.37 & 30. & 31 & 117 & & 65.49 \\
\hline & & 338.47 & 76. & 47.76 & 10. & 20 & 31 & 313.88 & 82.2 & & 67 \\
\hline 250.89 & 37.85 & 344.49 & 78.5 & 50.64 & 11.437 & 210.64 & 31.97 & \multirow{2}{*}{\multicolumn{2}{|c|}{ Series VI }} & & 71.73 \\
\hline 253.3 & 66 & \multirow{2}{*}{\multicolumn{2}{|c|}{ Series }} & 53.53 & 12.170 & 217.04 & 32.69 & & & 311.78 & 126.6 \\
\hline 260.19 & 39.48 & & & 56.91 & 12.911 & 233.67 & 33.66 & 2 & 48 & & 823 \\
\hline & 68.7 & 7.20 & 0.3 & 6 & 13 & 230 & 34 & 11 & & 312.10 & 2896 \\
\hline 29 & 57.6 & 7 & & 64.61 & 14.5 & $0=1$ & 27 & & & 312.108 & 5640 \\
\hline 316.0 & 85.6 & 7.93 & 0. & 68.50 & 15 & & & 282 & 122 & 312.114 & 13639 \\
\hline 334.32 & 73.25 & 8.83 & 0.6 & 72.43 & 16.0 & ric & & & & & 2586 \\
\hline 340.23 & 77.08 & & 0. & 76.59 & 16. & 27238 & 42.11 & 8 & 22 & 31. & 354.4 \\
\hline Serie & es III & 10 & 0.9 & 8 & 17 & & & & & & 192.7 \\
\hline 218.3 & 32.7 & & & & 18 & & 19 & .02 & 10 & $\begin{array}{l}75 \\
30\end{array}$ & $\begin{array}{l}94.0 \\
85.1\end{array}$ \\
\hline & & & & \multirow{2}{*}{\multicolumn{2}{|c|}{ Series VI }} & 283.19 & & & 9 & & $\begin{array}{l}8.1 \\
80.9\end{array}$ \\
\hline & 34. & & 1.7 & & & 284.23 & 13 & & & & 76.8 \\
\hline & & & 20 & 93.30 & 19.5 & 284.79 & 44 & 66 & 41 & 74 & 73.05 \\
\hline 241.76 & 36.0 & 15. & & & & 30 & 18 & & & & 70.0 \\
\hline & & & & & & & & 93 & 34 & & 70. \\
\hline 254.00 & 38 & & & & 21. & & & & 355 & 329.59 & 71.3 \\
\hline 260.10 & 39.26 & 18.98 & 3.010 & 113.27 & 21.79 & 290.30 & 55.54 & 285.17 & 346.2 & & \\
\hline
\end{tabular}

TABLE 2. Molar heat capacity of thallium(I) $n$-dodecanoate by d.s.c. ( 230 to $460 \mathrm{~K}$ ); $R=8.3144 \mathrm{~J} \cdot \mathrm{K}^{-1} \cdot \mathrm{mol}^{-1}$

\begin{tabular}{ccccccccccc}
\hline$T / \mathrm{K}$ & $C_{p, \mathrm{~m}}^{\prime} / R^{a}$ & $C_{p, \mathrm{~m}} / R^{b}$ & $T / \mathrm{K}$ & $C_{p, \mathrm{~m}} / R$ & $T / \mathrm{K}$ & $C_{p, \mathrm{~m}} / R$ & $T / \mathrm{K}$ & $C_{p, \mathrm{~m}} / R$ & $T / \mathrm{K}$ & $C_{p, \mathrm{~m}} / R$ \\
\hline 235 & 34.8 & 34.9 & \multicolumn{2}{c}{ Trs: VI to V to } & 350 & 77.0 & 390 & 58.1 & 435 & 71.3 \\
240 & 36.0 & 37.0 & \multicolumn{1}{c}{ IV to III to II } & Trs: Il to I & Trs: 1 to Meso & 440 & 71.7 \\
245 & 36.5 & 38.6 & 320 & 69.3 & 365 & 54.5 & 410 & 68.0 & 450 & 72.2 \\
250 & 37.3 & 39.6 & 325 & 70.1 & 370 & 54.3 & 415 & 68.8 & 455 & 72.9 \\
255 & 38.4 & 41.2 & 330 & 71.4 & 375 & 54.7 & 420 & 69.5 & 460 & 73.1 \\
260 & 39.4 & 42.6 & 335 & 74.0 & 380 & 55.4 & 425 & 70.1 & & \\
265 & 40.6 & 43.6 & 340 & 76.7 & 385 & 56.1 & 430 & 70.8 & & \\
270 & 42.2 & 45.7 & 345 & 78.0 & & & & & \\
\hline
\end{tabular}

${ }^{a}$ Crystal $V^{\prime}$ heat capacity (dotted line in figures 1 and 3 ).

${ }^{b}$ Crystal VI heat capacity (continuous line in figures 1 and 3). 


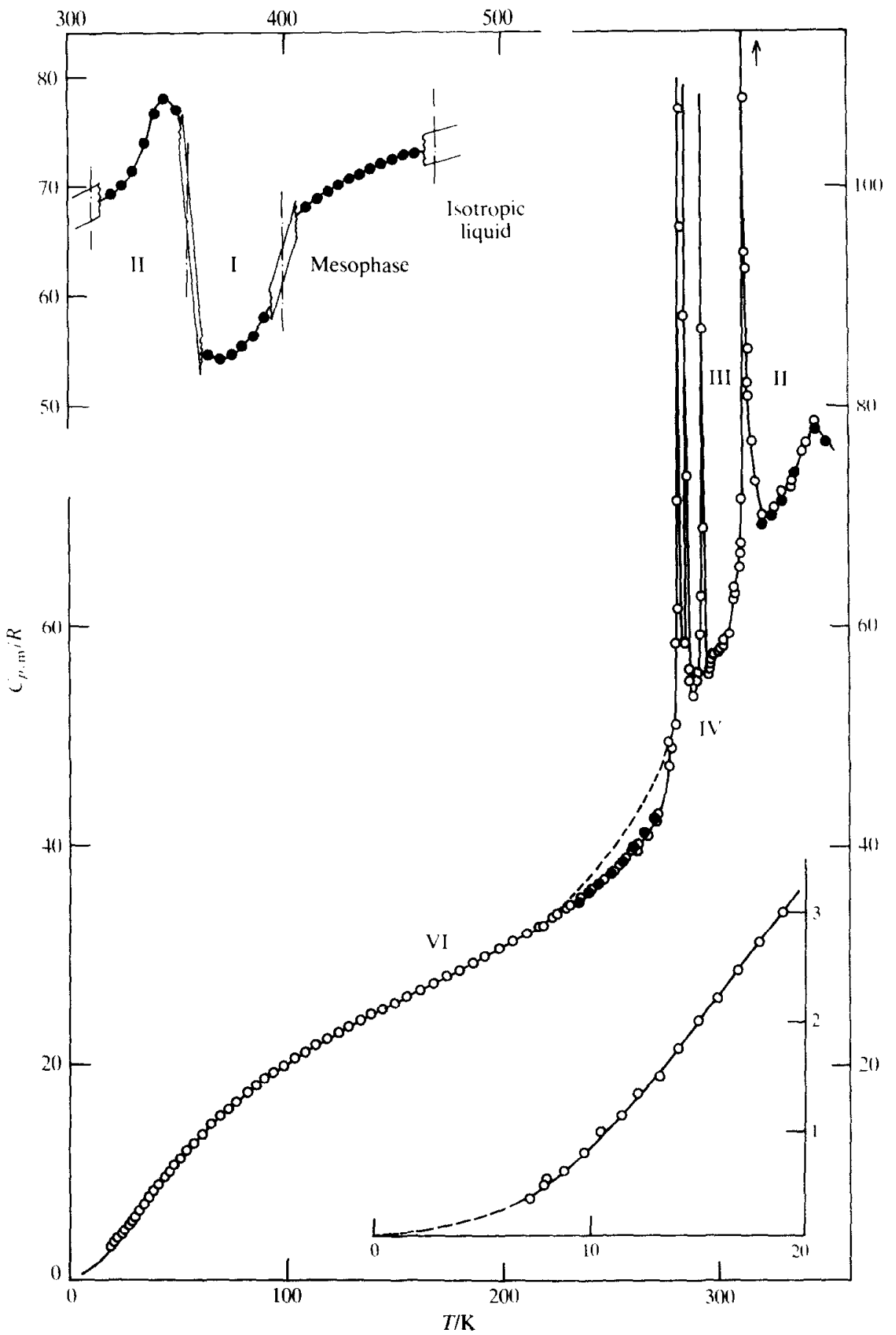

FIGURE 1. Heat-capacity curve for thallium(I) $n$-dodecanoate. $O$, Adiabatic calorimetric determinations; O. d.s.c. determinations; - - - d.s.c. determinations when Crystal $V^{\prime}$ is present. 
TABLE 3. Smooth standard molar thermodynamic values at selected temperatures for thallium(1) $n$-dodecanoate; $R=8.3144 \mathrm{~J} \cdot \mathrm{K}^{-1} \cdot \mathrm{mol}^{-1}$

\begin{tabular}{|c|c|c|c|c|c|c|c|c|c|}
\hline$T$ & $\underline{C_{p, \mathrm{~m}}}$ & $\underline{\Delta}_{0}^{T} S_{\mathrm{m}}^{\circ}(T)$ & $\Delta_{0}^{T} H_{\mathrm{m}}(T)$ & $\Phi_{\mathrm{m}}(T, 0)$ & $T$ & $C_{p, \mathrm{~m}}$ & $\Delta_{0}^{T} S_{\mathrm{m}}(T)$ & $\Delta_{i}^{T} H_{\mathrm{m}}^{\prime}(T)$ & $\Phi_{m}(T, 0)$ \\
\hline$\overline{\mathbf{K}}$ & $R$ & $R$ & $R \cdot \mathrm{K}$ & $R$ & $\overline{\mathrm{K}}$ & $R$ & $\bar{R}$ & $R \cdot \mathrm{K}$ & $R$ \\
\hline \multicolumn{10}{|c|}{ Phase VI } \\
\hline 0 & 0 & 0 & 0 & 0 & 120 & 22.58 & 22.69 & 1488.5 & 10.284 \\
\hline 5 & 0.117 & 0.039 & 0.148 & 0.0094 & 140 & 24.68 & 26.33 & & 12.319 \\
\hline 10 & 0.878 & 0.313 & 2.344 & 0.0786 & 160 & 26.69 & 29.75 & 2475.0 & 14.29 \\
\hline 15 & 1.981 & 0.868 & 9.370 & 0.243 & 180 & 28.66 & 33.01 & 3028.3 & 16.19 \\
\hline 20 & 3.305 & 1.616 & 22.54 & 0.489 & 200 & 30.78 & 36.14 & 3622.4 & 18.03 \\
\hline 25 & 4.661 & 2.499 & 42.45 & 0.801 & 220 & 33.05 & 39.18 & 4260.5 & 19.81 \\
\hline 30 & 6.081 & 3.473 & 69.25 & 1.164 & 240 & 35.88 & 42.17 & 948.2 & 21.55 \\
\hline 35 & 7.547 & 4.521 & 103.36 & 1.568 & $260^{a}$ & 39.37 & 45.18 & 5700.8 & 23.25 \\
\hline 40 & 8.84 & 5.616 & 41 & 2.005 & & {$[39.37]$} & {$[45,18]$} & {$[5700.8]$} & [23.25] \\
\hline 45 & 10.118 & 6.729 & 191.75 & 2.468 & 270 & 41.2 & 46.70 & 6103.8 & 24.09 \\
\hline 50 & & & & 2.951 & & {$[40.76]$} & {$[46,68]$} & {$[6101.1]$} & {$[24.08]$} \\
\hline 60 & 13.59 & 10.133 & 370.48 & 3.958 & 280 & 50.20 & 48.19 & 6518.5 & 24.91 \\
\hline 70 & .56 & & & 5.001 & & {$[42.21]$} & {$[48.17]$} & {$[6515,8]$} & {$[24.90]$} \\
\hline 80 & 17.34 & 7 & 681,0 & 6.061 & $282.6_{5}^{b}$ & $(\approx 250)$ & $(48.60)$ & $(6628.4)$ & $(25.15)$ \\
\hline 90 & 18.93 & & & 7.127 & & {$[42.60]$} & {$[48.60]$} & {$[6628.4]$} & {$[25.15]$} \\
\hline 100 & 20.30 & 78 & 9.0 & 8.189 & & & & & \\
\hline
\end{tabular}

Phase V

\begin{tabular}{|c|c|c|c|c|c|c|c|c|c|}
\hline $\begin{array}{l}282.6_{5}^{b} \\
283.8^{c}\end{array}$ & $\begin{array}{l}(\approx 250) \\
{[50.0]} \\
(58.0)\end{array}$ & $\begin{array}{l}(49.55) \\
{[48.60]} \\
(49.75)\end{array}$ & $\begin{array}{l}(6898.4) \\
{[6628.4]} \\
(6955.9)\end{array}$ & $\begin{array}{l}(25.15) \\
{[25.15]} \\
(25.24)\end{array}$ & $\begin{array}{l}283.8^{c} \\
284.8^{b}\end{array}$ & $\begin{array}{l}{[50.0]} \\
(\approx 450) \\
{[50.0]}\end{array}$ & $\begin{array}{l}{[48.80]} \\
(49.93) \\
{[48.98]}\end{array}$ & $\begin{array}{l}{[6685.9]} \\
(7005.9) \\
{[6735.9]}\end{array}$ & $\begin{array}{l}{[25.24]} \\
(25.33) \\
{[25.33]}\end{array}$ \\
\hline \multicolumn{10}{|c|}{ Phase IV } \\
\hline $284.8^{b}$ & $\begin{array}{l}(\approx 450) \\
{[53.4]} \\
(53.7)\end{array}$ & $\begin{array}{l}(51.04) \\
{[48.98]} \\
(51.73)\end{array}$ & $\begin{array}{l}(7322.0) \\
{[6735.9]} \\
(7519.6)\end{array}$ & $\begin{array}{l}(25.33) \\
{[25.33]} \\
(25.67)\end{array}$ & $\begin{array}{l}288.5^{\circ} \\
293.1^{b}\end{array}$ & $\begin{array}{l}{[53.4]} \\
(\approx 210) \\
{[53.4]}\end{array}$ & $\begin{array}{l}{[49.67]} \\
(52.57) \\
{[50.51]}\end{array}$ & $\begin{array}{c}{[6933.5]} \\
(7765.2) \\
{[7179.1]}\end{array}$ & $\begin{array}{l}{[25.64]} \\
(26.07) \\
{[26.02]}\end{array}$ \\
\hline \multicolumn{10}{|c|}{ Phase III } \\
\hline $293.1^{b}$ & $\begin{array}{c}(210) \\
{[54.40]} \\
(56.75) \\
{[56.53]}\end{array}$ & $\begin{array}{l}(53.30) \\
{[50.51]} \\
(54.25) \\
{[51.46]}\end{array}$ & $\begin{array}{l}(7981.2) \\
{[7179.1]} \\
(8261.1) \\
{[7459.1]}\end{array}$ & $\begin{array}{l}(26.07) \\
{[26.02]} \\
(26.54) \\
{[26.44]}\end{array}$ & $\begin{array}{l}310 \\
312.12^{b}\end{array}$ & $\begin{array}{c}66.4 \\
{[59.64]} \\
(\approx 14000)\end{array}$ & $\begin{array}{c}56.52 \\
{[53.73]}\end{array}$ & $\begin{array}{c}8953.2 \\
{[8151.1]}\end{array}$ & $\begin{array}{c}27.64 \\
{[27.44]}\end{array}$ \\
\hline 300 & 57.70 & 54.60 & 8366.5 & 26.71 & & {$[60.05]$} & [54.14] & [8277.9] & [27.62] \\
\hline
\end{tabular}

\begin{tabular}{|c|c|c|c|c|c|c|c|c|c|}
\hline \multicolumn{10}{|c|}{ Phase II } \\
\hline \multirow{2}{*}{$312.12^{b}$} & & & & & 340 & 76.75 & 64.97 & 11675 & 30.63 \\
\hline & $(\approx 14000)$ & $(59.01)$ & (9730.4) & $(27.84)$ & 345 & 78. & - & - & - \\
\hline \multirow[b]{2}{*}{320} & {$[63.36]$} & [54.14] & {$[8177.9]$} & [27.62] & 350 & 77.0 & $66.0_{9}$ & 12060 & $31.6_{2}$ \\
\hline & $(70.75)$ & (60.63) & $\begin{array}{l}(10243) \\
\\
587917\end{array}$ & $(28.62)$ & $356.6^{b}$ & $(-)$ & $(67.5)$ & $\begin{array}{l}(12570) \\
\end{array}$ & $\begin{array}{r}32.27 \\
\end{array}$ \\
\hline \multirow{2}{*}{330} & $\begin{array}{l}{[00.80]} \\
71.30\end{array}$ & $\begin{array}{c}{[55.76]} \\
62.76\end{array}$ & $\begin{array}{l}{[8791]} \\
10935\end{array}$ & $\begin{array}{c}{[28.29]} \\
29.62\end{array}$ & & & & & \\
\hline & {$[71.30]$} & {$[57.89]$} & [9482] & [29.16] & & & & & \\
\hline \multicolumn{10}{|c|}{ Phase I } \\
\hline $356.6^{\circ}$ & (-) & $\left(68,2_{0}\right)$ & $(12810)$ & $(32.27)$ & 390 & 58.1 & $73.0_{8}$ & 14630 & $\begin{array}{c}35.5_{6} \\
34.36\end{array}$ \\
\hline \multirow[t]{2}{*}{370} & $\begin{array}{l}{[32.2]} \\
54.3\end{array}$ & $\begin{array}{l}{\left[\begin{array}{l}0.0_{4} \\
70.1_{6}\end{array}\right]} \\
0\end{array}$ & 13520 & $\begin{array}{l}{[31.48]} \\
33.6_{1}\end{array}$ & $400.1^{b}$ & $\begin{array}{l}{[31.1]} \\
(-)\end{array}$ & $\begin{array}{l}{\left[01.3_{2}\right]} \\
\left(74.5_{5}\right)\end{array}$ & $\begin{array}{l}(12930\} \\
(15210)\end{array}$ & $\begin{array}{l}{\left[34.5_{6}\right]} \\
(36.53)\end{array}$ \\
\hline & {$\left[\begin{array}{c}54.0] \\
55.4\end{array}\right]$} & $\begin{array}{c}{\left[64.6_{0}\right]} \\
71.6\end{array}$ & {$\left[\begin{array}{c}{[11820]} \\
14070\end{array}\right.$} & {$[32.64]$} & & {$[58.6]$} & {$\left[68.9_{9}\right]$} & {$[13510]$} & [35.22] \\
\hline
\end{tabular}


TABLE 3-continued

\begin{tabular}{|c|c|c|c|c|c|c|c|c|c|}
\hline$T$ & $C_{p, \mathrm{~m}}$ & $\Delta_{0}^{\mathrm{T}} S_{\mathrm{m}}^{\circ}(T)$ & $\Delta_{0}^{T} H_{\mathrm{m}}^{\circ}(T)$ & $\Phi_{\mathrm{m}}^{\circ}(T, 0)$ & $T$ & $C_{p, \mathrm{~m}}$ & $\Delta_{0}^{T} S_{\mathrm{m}}(T)$ & $\Delta_{0}^{T} H_{\mathrm{m}}^{j}(T)$ & $\Phi_{\mathrm{m}}(T, 0)$ \\
\hline$\overline{\mathbf{K}}$ & $R$ & $R$ & $R \cdot \mathrm{K}$ & $R$ & $\overline{\mathrm{K}}$ & $R$ & $R$ & $R \cdot \bar{K}$ & $R$ \\
\hline \multicolumn{10}{|c|}{ Mesophase } \\
\hline $400.1^{b}$ & $(-)$ & $\left(76.1_{9}\right)$ & (15870) & $\left(36.5_{3}\right)$ & 440 & 71.7 & $82.7_{8}$ & 18640 & $40.4_{2}$ \\
\hline & [66.5] & {$\left[68.9_{9}\right]$} & [13510] & {$\left[35.2_{2}\right]$} & 460 & 73.1 & $86.0_{0}$ & 20080 & $42.3_{4}$ \\
\hline 410 & $\begin{array}{c}68.0 \\
{[68.0}\end{array}$ & $\begin{array}{c}77.8_{3} \\
{\left[70.6_{3}\right]}\end{array}$ & $\begin{array}{c}16530 \\
{[14180]}\end{array}$ & $\begin{array}{c}37.5_{1} \\
{\left[36.0_{5}\right]}\end{array}$ & $471.5^{b}$ & $\begin{array}{r}(--) \\
{[73.5]}\end{array}$ & $\begin{array}{c}87.8_{1} \\
{\left[80.6_{1}\right]}\end{array}$ & $\begin{array}{c}20910 \\
{[18570]}\end{array}$ & $\begin{array}{c}43.4_{2} \\
{[41.2,]}\end{array}$ \\
\hline 420 & 69.5 & $79.4_{9}$ & 17220 & $38.4_{9}$ & & & & & \\
\hline \multicolumn{10}{|c|}{ Isotropic liquid } \\
\hline $471.5^{b}$ & $(-)$ & $\left(88.3_{1}\right)$ & $(21160)$ & $\left(43.4_{2}\right)$ & & & & & \\
\hline
\end{tabular}

"Values in square brackets represent selected lattice heat capacities or the integrated thermodynamic functions of the selected lattice.

${ }^{b}$ Values in parentheses represent either estimated heat capacities or thermodynamic functions on the arbitrary assumption that the transitions are truly isothermal at the transition temperature indicated.

'Values at minimum points between bifurcated transitions.

with the maximum at about $360 \mathrm{~K}$. Phases II of both compounds are reported to be structurally similar by studies on miscibilities by Lindau et al. ${ }^{(11)}$

The heat capacities have been fitted to a series of orthogonal polynomials in the region of normal heat capacities. Integration of these polynomials yields the thermodynamic functions. Table 3 summarizes the smoothed values of $C_{p, m} / R$ and derived functions at selected temperatures. The heat capacities within the transition region given in this table are those for both the measured heat capacity of the compound and the lattice contribution by extra regions of "normal" heat capacity.

Four presumably first-order transitions were observed in the heat-capacity curve

TABLE 4. Standard molar enthalpies and entropies of the lower-temperature $(260$ to $300 \mathrm{~K})$ transitions in thallium(I) $n$-dodecanoate; $R=8.3144 \mathrm{~J} \cdot \mathrm{K}^{-1} \cdot \mathrm{mol}^{-1}$

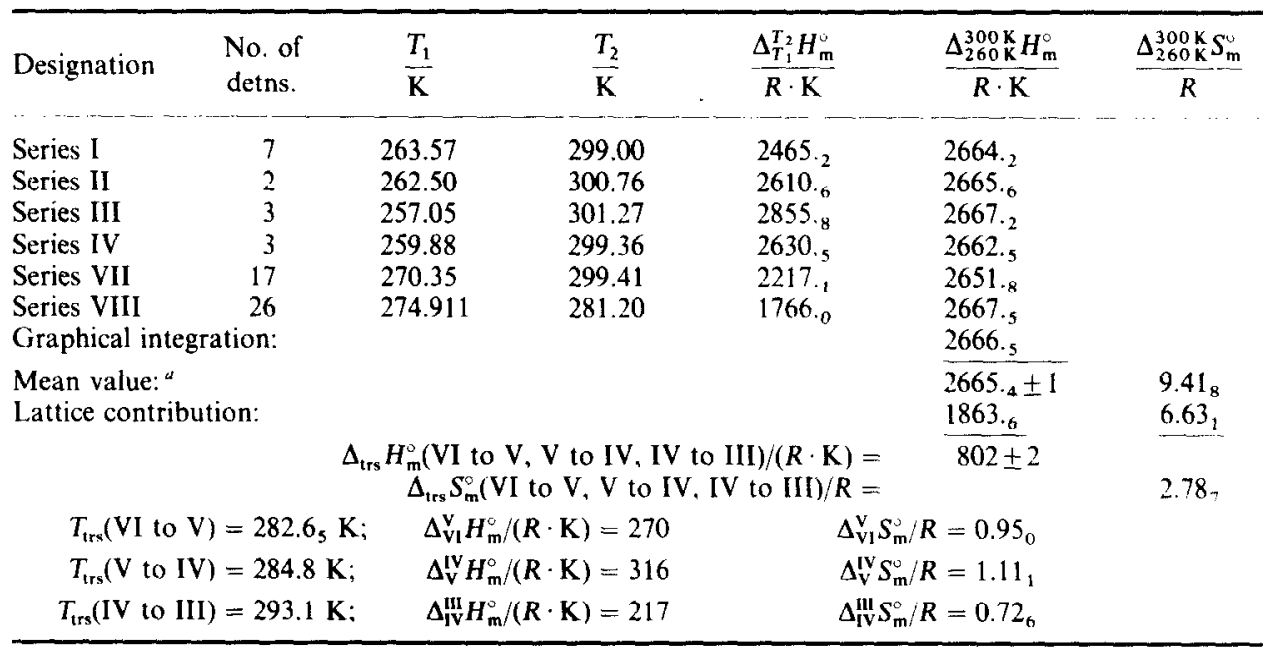

\footnotetext{
a Average omitting Series VII and graphical integration values.
} 


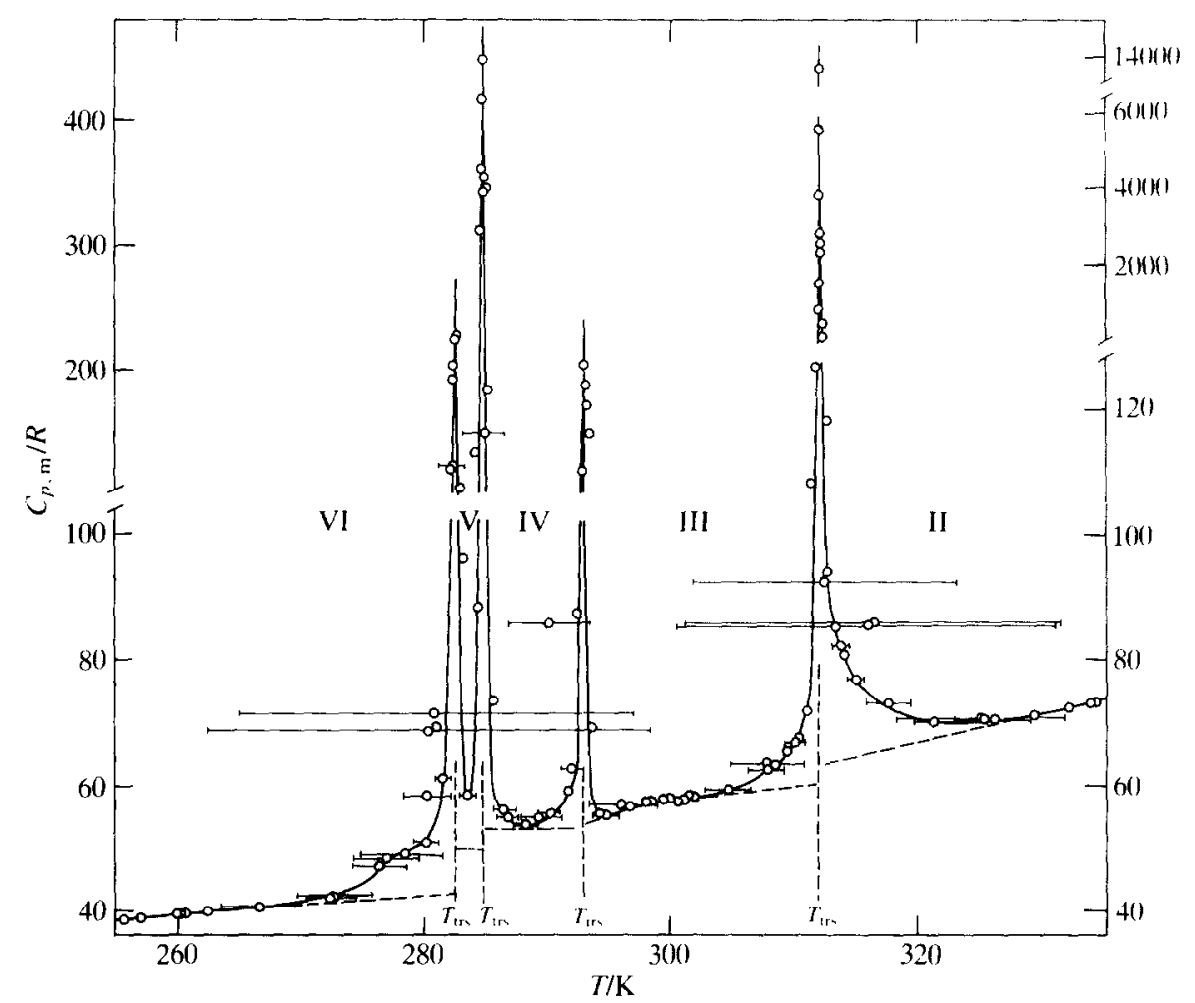

FIGURE 2. Expanded heat-capacity curve of thallium(I) n-dodecanoate showing the transition region below $350 \mathrm{~K}$ as determined by adiabatic calorimetry. Note adjuvant scales for peak values and phase designations. - - - Estimated lattice heat-capacity contributions; $\longmapsto$, temperature increments of enthalpy-type determinations.

defined by our adiabatic calorimetric measurements (below $350 \mathrm{~K}$ ). The total enthalpy increments through the transition regions for the various series of determinations are given in tables 4 and 5. Both tables show that the reproducibility

TABLE 5. Standard molar enthalpy and entropy of the $312.11 \mathrm{~K}$ transition (III-to-II transition) in thallium(l) $n$-dodecanoate; $R=8.3144 \mathrm{~J} \cdot \mathrm{K}^{-1} \cdot \mathrm{mol}^{-1}$

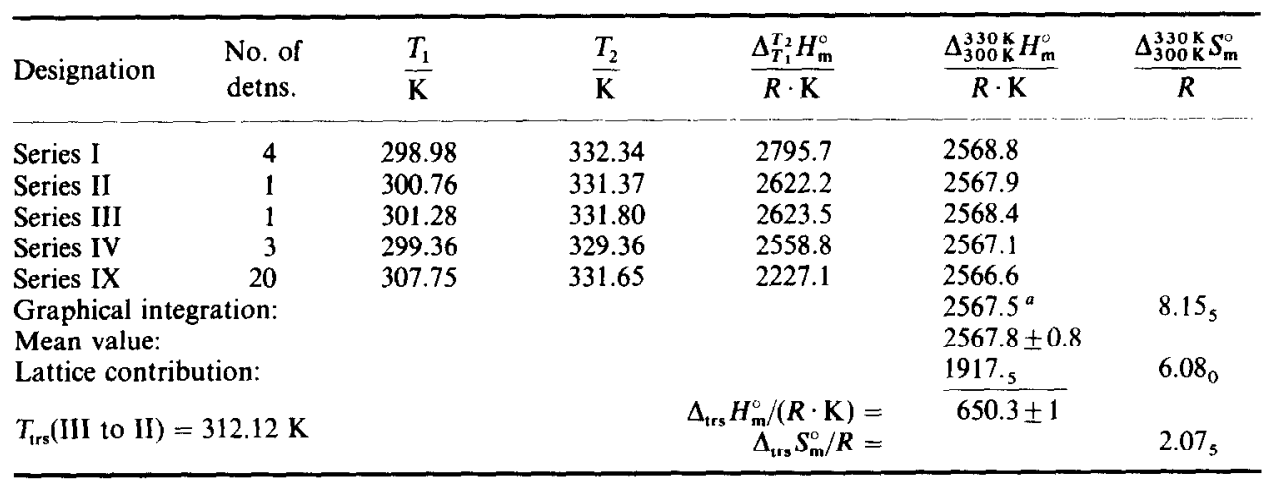

${ }^{a}$ Not included in the mean. 


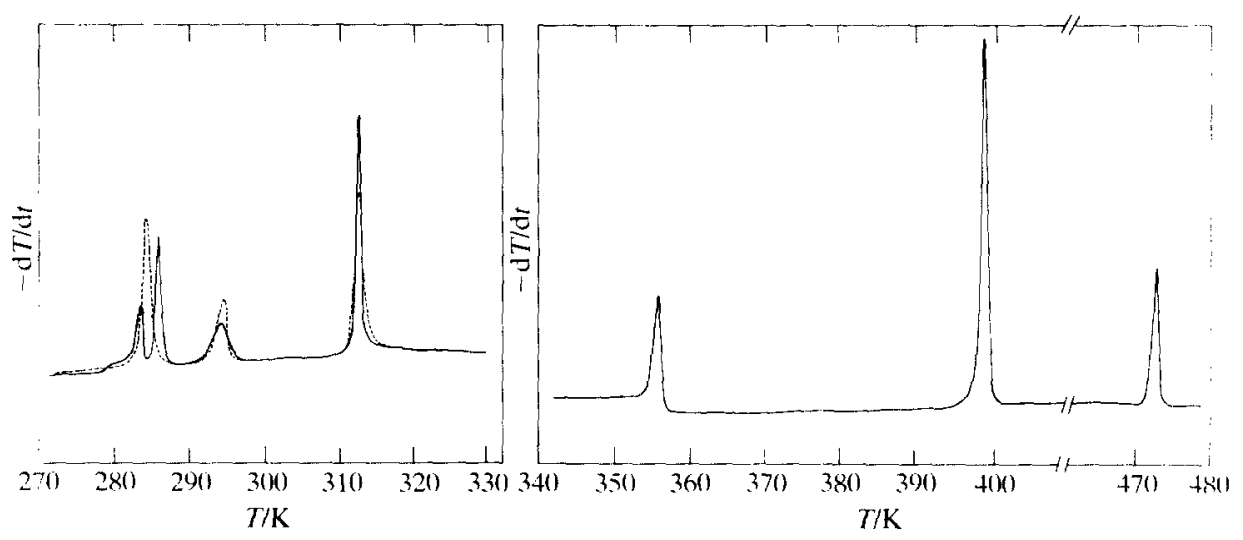

FIGURE 3. D.s.c. thermograms ("on heating") of thallium(I) n-dodecanoate. (a), - - --, The behavior when Crystal $V^{\prime}$ is present. (b), Solid-to-solid, solid-to-mesophase, and mesophase-to-isotropicliquid transitions above the upper limit of the adiabatic calorimetric measurements.

of the heat-capacity curve in the transitional regions in our measurements was within the experimental error. In addition to the four solid-to-solid transitions a small shoulder is observed below the VI-to-V transition. This is in agreement with the observations over successive heating thermograms taken by d.s.c.

In the region between 280 and $300 \mathrm{~K}$, two different behaviors were found by d.s.c. (as summarized in figures 1 and 3 and in tables 2 and 6). In samples of very high purity (i.e. salt, $>99.8$ moles per cent), a simple transition at $284.6 \mathrm{~K}$ (Crystal V') is first observed, but it transforms irreversibly into two at 283.0 (Crystal VI) and $285.2 \mathrm{~K}$ (Crystal V), with a small shoulder below them in successive scans (occasionally in the third, but mostly in the second scan). As can be seen in the figures and tables cited, the thermal functions of the $V^{\prime}$-to-IV transition are lower than the sum of those of both VI-to-V and V-to-IV; but, correspondingly, the heat capacity of the $\mathrm{V}^{\prime}$ phase is higher than that of the VI phase. This $C_{p, m}$ variation approximately compensates for the difference. In less pure-but still high-purity samples-(i.e. salt, $>99.5$ moles per cent), the behavior directly affects phases VI and $V^{\prime}$.

Above the upper limit of adiabatic calorimetric measurements, three more transitions were found by d.s.c.: a solid-to-solid one at $356.6 \mathrm{~K}$; a

TABLE 6. Transition properties of thallium(I) n-dodecanoate by d.s.c. (mean values of five determinations)

\begin{tabular}{lccc}
\hline \multicolumn{1}{c}{ Transition } & $T / \mathrm{K}$ & $\Delta_{\mathrm{trs}} H_{\mathrm{m}}^{\circ} /(R \cdot \mathrm{K})$ & $\Delta_{\mathrm{trs}} S_{\mathrm{m}}^{\circ} / R$ \\
Crystal $\mathrm{V}^{\prime} \rightarrow$ Crystal IV & $284.6 \pm 0.5$ & $380 \pm 40$ & $1.34 \pm 0.15$ \\
Crystal VI $\rightarrow$ Crystal V & $283.0 \pm 0.3$ & $220 \pm 10$ & $0.78 \pm 0.04$ \\
Crystal V $\rightarrow$ Crystal IV & $285.2 \pm 0.2$ & $251 \pm 17$ & $0.88 \pm 0.06$ \\
Crystal IV $\rightarrow$ Crystal III & $293.6 \pm 0.6$ & $170 \pm 17$ & $0.58 \pm 0.06$ \\
Crystal III $\rightarrow$ Crystal II & $312.3 \pm 0.4$ & $540 \pm 50$ & $1.73 \pm 0.15$ \\
Crystal II $\rightarrow$ Crystal I & $356.6 \pm 0.3$ & $247 \pm 18$ & $0.69 \pm 0.05$ \\
Crystal I $\rightarrow$ Mesophase & $400.1 \pm 0.2$ & $656 \pm 30$ & $1.64 \pm 0.07$ \\
Mesophase $\rightarrow$ Isotropic liquid & $471.6 \pm 0.3$ & $237 \pm 10$ & $0.50 \pm 0.02$ \\
\hline
\end{tabular}


TABLE 7. Summary of transition temperatures for thallium(I) n-dodecanoate(s)

\begin{tabular}{|c|c|c|c|c|c|}
\hline Phase change & $\begin{array}{l}\text { This work } \\
\text { (adiabatic } \\
\text { calorimetry) }\end{array}$ & $\begin{array}{c}\text { This work } \\
\text { (d.s.c.) }\end{array}$ & $\begin{array}{l}\text { Lindau } \\
\text { et al. }{ }^{(s)} \\
\text { (d.s.c) }\end{array}$ & $\begin{array}{l}\text { Meise) } \\
\text { et al. } 7 \text { 1 } \\
\text { (d.t.a.) }\end{array}$ & $\begin{array}{l}\text { Pelzl and } \\
\text { Sackmann }{ }^{(\hbar)} \\
\text { (micr.) }\end{array}$ \\
\hline $\mathrm{VI} \rightarrow \mathrm{V}$ & $282.6_{5}$ & 283.0 & -.- & ..- & $\ldots$ \\
\hline$V \rightarrow I V$ & 284.8 & 285.2 & -- & -- & $\ldots$ \\
\hline IV $\rightarrow$ III & 293.1 & 293.6 & $-\cdots$ & -- & $\cdots$ \\
\hline III $\rightarrow$ II & 312.11 & 312.3 & 309.2 & 312 & $\ldots$ \\
\hline $\mathrm{II} \rightarrow \mathrm{I}$ & - & 356.6 & 347.0 & 354 & - \\
\hline$I \rightarrow$ Mesophase & - & 400.1 & 395.5 & 398 & 397.9 \\
\hline Mesophase $\rightarrow$ Isotropic liquid & - & 471.6 & 470.0 & 471 & 470.0 \\
\hline
\end{tabular}

solid-to-mesophase ("neat", similar to a smectic A phase) at $400.1 \mathrm{~K}$; and the "clearing" or fusion of the neat phase into the isotropic liquid at $471.5 \mathrm{~K}$.

In table 6 the transition properties obtained by d.s.c. are summarized. By comparison of the adiabatic calorimetric and d.s.c. results, the values of the d.s.c. enthalpy and entropy for the transitions are approximately 1.2 times lower than those obtained by adiabatic calorimetry. This is probably mainly due to differences in the base line chosen for resolution of the excess heat capacity. The agreement here is less satisfactory than for previous members of the series. ${ }^{(1-3)}$

Preliminary d.s.c. work showed clearly the presence of a very energetic transition at about $330 \mathrm{~K}$ for (thallium(I) $n$-dodecanoate $+n$-dodecanoic acid) similar to that observed for $n$-heptanoate. ${ }^{(2)}$ This transition may also involve incongruent melting of the 1-1 (salt + acid) complex.

Finally, a summary of the observed transition temperatures and literature values for comparison is shown in table?.

We thank Roey Shaviv and Stanley P. Ngeyi for assistance with the experimental measurements. This research was supported in part by the "Comision Asesora de Investigación Científica y Técnica" of the "Ministerio de Educacion y Ciencia" of Spain (Grants-in-aid for Scientific Research PB85-0042).

\section{REFERENCES}

1. Boerio-Goates, J.; López de la Fuente, F. L.: Cheda, J. A. R.; Westrum, E. F., Jr. J. Chem. Thermodynamics 1985, 17, 401.

2. Ngeyi, S. P.; López de la Fuente, F. L.; Cheda, J. A. R.; Fernández-Martín, F.; Westrum. E. F., Jr. J. Chem. Thermodynamics 1985, 17, 409.

3. Ngeyi, S. P.; Westrum, E. F., Jr.; López de la Fuente, F. L.; Cheda, J. A. R.; Fernández-Martín, F J. Chem. Thermodynamics 1987, $19,327$.

4. Franzosini, P.; Sanesi, M. Thermodynamic and Transport Properties of Organic Salts. Pergamon Press: London. 1980.

5. Lindau, F.; Diele, S.; Kruger, H; Dorfler, H.-D. Z. Phys. Chem. 1981, 262, 775.

6. Pelzl, G.; Sackmann, H. Mol. Cryst. Liq. Cryst. 1971, 15, 75.

7. Meisel, T.; Seybold, K.; Halmos, Z.; Roth, F.; Melykuti, C. J. Therm. Anal. 1976, 10, 419.

8. Westrum, E. F., Jr.; McCullough, J. P. Experimental Thermodynamics. Scott, D. W.; McCullough. J. P.: editors. Butterworths: New York. 1968, p. 337.

9. Westrum, E. F., Jr. Proceedings NATO Advanced Study Institute on Thermochemistry at Viana do Castello, Portugal. Ribeiro da Silva, M. A. V.: editor. Reidel: New York. 1984, 745.

10. Ditmars, D. A.; Ishiwara, S.; Chang, S. S.; Bernstein, G. J. Res. Natl. Bur. Stand. 1982, 87. 159.

11. Lindau, J.; König, H. J.; Dörfler, H. D. Colloid and Polymer Sci. 1983, 261, 236-240. 